\title{
A Study on "Value" Concept of the Austrian School
}

\author{
Yu Feng ${ }^{1}$ \\ ${ }^{1}$ School of Philosophy, Beijing Normal University, Beijing, China \\ Correspondence: Yu Feng, School of Philosophy, Beijing Normal University, No. 19, XinJieKouWai St. HaiDian \\ District, Beijing 100875, P. R. China. Tel: 135-2186-7715. E-mail: 201521020001@mail.bnu.edu.cn
}

Received: February 21, 2020

Accepted: March 24, 2020

Online Published: March 30, 2020

doi:10.5539/ass.v16n4p42

URL: https://doi.org/10.5539/ass.v16n4p42

\begin{abstract}
The marginal utility theory of Austrian School is an important value theory in western economics. Need theory is the basis and premise of value theory. Need, which is equivalent to desire, has two specific connotations: "one of many needs" and "feelings of a certain need". The contribution and innovation of the need theory of Austrian School lies in that it puts forward two classifications of needs through studying the significance of needs, points out that value is only related to the classification of degrees of needs, reveals the general rule that the importance of one need decreases gradually with the increase in satisfaction, and puts forward the core concept of "marginal utility". The Austrian School studies the quality and quantity of value with human needs or desires as the measure of value. In the qualitative aspect of value, whether people's needs can be met is the direct basis for judging the existence of value, and whether it can improve people's life and welfare is the fundamental reason to judge the value of goods. In terms of the quantity of value, economists of the Austrian School propose the principle that marginal utility determines the value of the last unit of goods, completely solve Adam Smith's value paradox and achieve the transcendence of subjective utility theory.
\end{abstract}

Keywords: Austrian School, goods, marginal utility, need, value

\section{Introduction}

Marginal utility theory of the Austrian School, which emerged in the 1870 s, is a value theory of Western economics. It defines the concept of value based on human needs or desires. This value concept is not only a concept of economics, but also has philosophical significance. As an economic value theory, marginal utility theory aims to provide a reasonable explanation of price theory and actual exchange relations. "The marginal utility theory is not only the gist of value theory, but also the gist of all economic theories because it can provide explanations for all economic transactions", (Bohm-Bawerk, 1983, p. 168) said Bohm-Bawerk, an important representative of the Austrian School. This theory occupies an important position in Western economics and has a profound impact, therefore, it is of great theoretical significance to study this theory.

The research methods to be adopted in this paper are as follows: first, the literature research method. By reading the original works, we can accurately grasp the value thought of the Austrian school, which lays a foundation for further analysis and argumentation. Second, the comparative research method. Any kind of mature thought has gone through a process of evolution and development. The latter thought must include criticism, amendment or development of the predecessor, so it is necessary to compare the views of the former and the latter. Third, the method of combining theory with facts. The research process involves both abstract theories and specific facts. Facts are the sole criterion for testing truth. Therefore, the conclusions drawn from the research should be consistent with the facts, and the view that cannot withstand the test of facts is not convincing. Fourth, interdisciplinary research methods. This research involves multiple disciplines (philosophy, economics, psychology, etc.). Therefore, the article attempts to analyze the problem from different perspectives and use flexible methods to find the answer. Through the above methods, the article aims to solve the following problems: reveal the basis and premise of the value theory of the Austrian school; answer the question of how marginal utility theory judges the existence of value and how to measure the value; Finally, since subjective utility theory is the ideological foundation and theoretical source of marginal utility theory, where does the latter manifest its transcendence over the former. 


\section{The Need Theory of the Austrian School}

\subsection{The Connotation of Need}

On the issue of value, some scholars realized that there was an inseparable connection between "needs" and "value". In the book "Introduction to Axiology", Yuan Guiren pointed out: "What kind of need theory also has what kind of value theory, the problems of value are largely addressed by needs". (Yuan, 1991, p. 53) The important representative of the Austrian School, Wieser, agreed: "to discover the law of value, one must first understand the law of need". (Wieser, 1982, p. 37) Therefore, the need theory of the Austrian School is the basis and premise of the value theory.

According to the Austrian School, "the usual use of the word 'needs' refers to all human desires", (Wieser, 1982, p. 7) "need" and "desire" are an equivalent concept. "Need" or "desire" is not some kind of objective existence, not an inherent property of things, but a subjective psychological feeling of people, or a subjective reflection on the state of insufficiency. The above expression is the basic connotation of "need", in addition, "need" has two specific connotations: "one of many needs" and "feelings of a certain need". "One of many needs" refers to the "kind" of need and is related to the quality of the goods; "feelings of a certain need" refers to the "degree" of need and is related to the quantity of goods. The division of the two specific connotations of "need" is the transcendence of the Austrian School's value theory over the past subjective utility value theory, only by going deep into the degree of need and the quantity of goods can economists discover the concept of "marginal", propose the law of value that "marginal utility" determines the value of the last increment of goods, solve Adam Smith's "value paradox", and promote the study of economic value from macro to micro.

\subsection{The Properties of Need}

The Austrian School holds that need has the following properties: First, the property that need to be satisfied. Human needs inherently have a natural tendency to long for full satisfaction. This natural tendency drives people to satisfy their own needs by constantly occupying and controlling external objects. "Human effort is to seek the full satisfaction of their desires; if complete satisfaction is not possible, then satisfy their desires as completely as possible". (Menger, 2013, p. 65) Second, objectivity. Human needs cannot be met subjectively by means of "painting cakes to eliminate hunger" or "watching plums to quench thirst", but must rely on external objects. Needs can be satisfied only with the actual possession and domination of external objects. Therefore, human needs always point to a certain object, it is the need for a certain object. Third, subjectivity. Need is a mental state of a person in the form of spirit or consciousness, which is different from matter. However, subjectivity is not equal to subjective arbitrariness. People cannot change or eliminate desires at will. Satisfying desires as much as possible is the only way to get rid of desires temporarily. Fourth, rationality. The Austrian School believes that all human needs are rational and should be fully satisfied. "Unsatisfied desires will harm our constitution; desires that are not fully satisfied will shrink our constitution"; (Menger, 2013, p. 22) Human life and welfare can be improved only when the needs are fully satisfied. Fifth, from the "qualitative" perspective of needs, the types of needs are not fixed, but in the process of constant change and development. The types of needs are not only influenced by subjective factors, but also restricted by objective factors such as the level of social development. From the perspective of "quantity", the intensity of one need varies with the degree of satisfaction, and the intensity of needs can only be compared but cannot be accurately calculated. Therefore, need is uncertain.

\subsection{The Importance or Significance of Need}

The Austrian School focused the study of need theory on the importance or significance of need. Since Menger, the Austrian School economists have clearly put forward that different kinds of needs have different importance, and even the same kind also has different significance in different stages of satisfaction. Menger believes that "the different significance of desire satisfaction can be seen not only in the satisfaction of different desires, but also in more or less satisfaction of the same desire". (Menger, 2013, p. 60) Bohm-Bawerk summarizes it more deeply into the concept of "needs classification". "The so-called 'needs classification' can refer to the classification of types of needs, but also to the classification of degree of one need (that is, the individual's specific feeling of one need), and the two are fundamentally different, or even run counter to each other". (Bohm-Bawerk, 1983, p. 160) "The classification of types of needs" refers to different kinds of needs have different importance. And "the classification of degree of one need" refers to "within the same need, there are many specific needs (or degrees of the need) of different importance". (Bohm-Bawerk, 1983, p. 162) Bohm-Bawerk further pointed out: "the value we estimate of an item has nothing to do with the classification of types of needs, it is only related to the classification of the specific needs". (Bohm-Bawerk, 1983, p. 162) Corresponding to the two classifications of needs, the basic connotation of "needs" has evolved into two 
different concrete connotations: "one of many needs" and "a sense of one need". Wieser made it clear that "we should distinguish between the whole need and the individual feelings of need that are contained in it". (Wieser, 1982, p. 9) It should be noted that in the discussion of "quality" and "quantity" of value below, we use this concept in the second specific connotation.

In addition to creatively putting forward the concept of "classification of needs", the Austrian School also discusses the dynamic relationship between "the importance of need" and "the degree of satisfaction" in a certain kind of needs. "In general," Menger points out, "the satisfaction of a desire, up to a certain point, is of considerable significance to us; but satisfaction beyond this point is of less and less significance to us; if we go on, we will reach the stage where it is no longer necessary to satisfy this desire; in the end, it comes to a point where the outward appearance of desire satisfaction has no significance for us, and has become a burden or a painful situation". (Menger, 2013, p. 61) Bohm-Bawerk also believes that "the degrees of our specific needs (that is, the degrees into which our feelings of needs can be divided) or the degrees of satisfaction obtained from the same amount of goods usually have very different importance, which decreases gradually to zero". (Bohm-Bawerk, 1983, p. 162) In short, with respect to one need, "the importance of the need" or "one's specific sense of the need" decreases gradually with the satisfaction increases, until it reaches saturation, "the importance of the need" decreases to zero. It is a general rule that the importance of need changes in the opposite direction with the quantity of goods or the degree of satisfaction and the core concept of the Austrian school was put forward on the basis of it.

\section{The Qualitative Study on Value Theory of the Austrian School}

\subsection{The Value Object of the Austrian School Is Goods}

The so-called "quality" of value refers to the study of whether there is value or not. Any kind of value theory has definite evaluation object, namely its value object. The value theory of Austrian School holds that "goods" is the object of value. The Austrian scholars believe that whether there is a causal relationship between things and needs satisfaction is an important basis for whether things can become "goods". In daily life, "goods" that can be directly used to meet human needs, such as food, clothes, houses, etc., are called "first class goods" or "enjoyment materials"; There is another kind of goods that can only indirectly meet people's needs, such as raw materials, labor, land, production tools, etc., are called "advanced goods". According to the closeness of "advanced goods" and needs satisfaction, they further call the "advanced goods" used to produce the "first class goods" the "second class goods", and call the "advanced goods" used to produce the "second class goods" the "third class goods", and so on. The reason why "advanced goods" have the property of goods is that they can be used to produce "first class goods" to indirectly meet people's needs, therefore, "the property of goods is restricted by whether it maintains a causal relationship with the satisfaction of human desires". (Menger, 2013, p. 12) From another perspective, economists of the Austrian School distinguish between "economic goods" and "non-economic goods" based on the supply and demand of them, they call goods whose supply is less than demand "economic goods" and goods with an opposite quantitative relationship "non-economic goods". Value object is important in a value theory. It can determine the category of this value theory to a certain extent. It is precisely because goods are the object of economics that the value theory of the Austrian school must be an economic value theory.

\subsection{The Measure of Value and Its Changing Law}

Before discussing the "quality" of value in this part and the "quantity" of value in the third part, we should make clear the measure of value of the Austrian School's value theory (marginal utility theory), because for any value theory, value measure is not only the basis for judging whether there is value, but also the scale for measuring value. Scholars of the Austrian School clearly point out that the measure of value is "the importance of need", "the significance of desire satisfaction" or "the value of need". This measure is not fixed, but in a process of constant change, the general changing law is that "the importance of needs" decreases with "the quantity of goods" or "the degree of satisfaction" increases, which was already revealed in the first part of the article. To grasp this law visually, Menger divided "the significance of desire satisfaction" into ten grades, represented by ten numbers from "1" to "10". He went on to match these numbers with the significance of need from the first satisfaction to the last satisfaction, then arrived at a sequence or "saturation scale" with different starting points but decreasing uniformly at the same speed. The starting points of different saturation scales are different because human needs have different kinds. Wieser thought that Menger had violated the empirical facts when expounding the decreasing law of "the significance of desire satisfaction", so he revised the "saturation scale" based on Menger. According to Wieser, only dividing "the significance of desire satisfaction" into ten grades can neither accurately show the differences in "saturation scales" of different needs, nor accurately describe the 
changing law of "saturation scale" of one certain need in the process of satisfaction. "The significance of desire satisfaction" does not decrease at a constant speed with the satisfaction increases. On the contrary, in the process of satisfaction, some needs quickly reach the point of full satisfaction from the highest point of significance; some needs are met from the beginning to the end but no one feels the reduction in intensity; some needs decrease faster at the beginning of fulfillment and some decrease faster at the end of fulfillment. In short, the same "saturation scale" or diminishing law does not exist in any two kinds of needs or in repeated satisfaction of the same need.

\subsection{The Cause, Essence and Properties of Value}

The measure of value has dual functions, judging whether there is value or not and measuring the quantity of value, this chapter focuses on its first function. Menger, the founder of the Austrian School, pointed out that "the reason why a kind of goods is valuable to us is that the control over it has some significance for the satisfaction of our desires". (Menger, 2013, p. 56) In short, people's needs can be met is the direct cause of the value of goods. Menger further pointed out: "the significance of goods to us is only a significance of transfer. Basically, only the satisfaction of desires has significance to us. However, the satisfaction of desires must depend on the domination of goods, therefore, we consciously transfer this significance to the goods under the logical deduction". (Menger, 2013, p. 71) The goods themselves are of no value, what is really valuable is the satisfaction of needs, it is precisely because people directly experience the important role of goods in meeting human needs in economic life that they transfer the significance that originally belongs to needs to the goods. "The value of goods is derived from the value of needs", (Wieser, 1982, p. 7) then where does the "value of needs" be derived? Menger believes that the satisfaction of needs is valuable because our lives and welfare are dependent on it. It is precisely because the satisfaction of needs is conducive to the improvement of human life and welfare that the satisfaction of needs has value, and ultimately the goods on which these desires depend have value. Therefore, whether people's lives and welfare can be improved is the fundamental cause of the value of goods. In a word, the Austrian School divides value into three levels, from low to high, which are the value of goods, the value of needs or the significance of desires satisfaction, and people's lives and welfare. The relationship between the three is the "cause-effect " or "means-purpose" relationship, the higher level is the result and purpose of the lower level, and the lower level is the reason and means of the higher level.

Scholars of the Austrian School further point out that value is not an independent and self-existing entity, not the property of the goods themselves, but "the judgment of the economic man on the significance of goods". (Menger, 2013, p. 57) Because value is essentially a judgment or an evaluation, it is a purely subjective thing, "it never exists outside the consciousness of economic people" (Menger, 2013, p. 57). So the value theory of the Austrian School is a subjective value theory. Besides, it is also an individualistic value theory, because evaluation is always relative to the individual, and each evaluation is an individual behavior independent of others. The subjectivity and individuality of value determine the relativity of value to a certain extent. Human needs systems change widely and frequently, the goods that are depended on different needs must have different value; as for the same need, different subjects will always make different evaluations; even in the case that one subject is just relative to one need, the value subject may also make different evaluations between this and last satisfaction due to the different degrees of satisfaction.

\section{The Quantitative Study on Value Theory of the Austrian School}

\subsection{The Value Paradox of Subjective Utility Theory}

The subjective utility value theory is the ideological foundation and theoretical source of the Austrian School's value theory; utility theory holds that as long as a thing can meet human needs, it has utility, and utility is value; the greater the utility, the greater the value. However, Adam Smith revealed the paradox of utility theory on the quantity of value. Adam Smith states: "the word value has two different connotations. It sometimes indicates the utility of a particular thing, sometimes indicates the purchasing power that enables it to exchange with other goods, which comes from the ownership of it. The former can be called use value, and the latter can be called exchange value. Things with great use value often have little or no exchange value; conversely, things with great exchange value often have little or no use value. For example, water is the most useful, but we can't buy anything with water, and we won't trade anything for water. On the contrary, although diamond has almost no use value at all, it needs a lot of other goods to be exchanged for it". (Smith, 1983, p. 25) The "value paradox" reveals the contradiction between "use value" and "exchange value". In daily life, people often give goods with a larger utility a lower valuation or price, and conversely often give goods with a smaller utility a higher valuation or price. What prompted the marginal utility theory to study the quantity of value is that subjective utility theory fails to put forward the concept of "marginal" and therefore cannot completely solve the "value paradox". 


\section{2 "Marginal Utility" and the Law of Value}

The concept of "marginal utility" is based on the law of diminishing utility and it is the key to solving "value paradox". Menger clearly expressed the connotation of "marginal utility" in "Principles of National Economics", where "marginal utility" was expressed as "the significance of the least important desire satisfaction among various desires satisfactions", but he did not explicitly put forward the concept of "marginal utility". Wieser first proposed the word "Grenznutzen" in his book "The Origins and Main Laws of Economic Value", which was later translated by P. H. Wicksteed as "marginal utility" (Howey, 1999, p. 19). The core of this concept lies in the adjective "marginal". What is "marginal"? "Marginal" is "a concept that reflects the quantity of things. In economics, marginal quantity refers to the final increment in production, exchange, distribution, and consumption under certain conditions". (Yan, 1987, p. 1) Therefore, "marginal utility" is the significance of the last increment of goods and core concept of the value theory of the Austrian School.

The Austrian economists believe that it is not the total utility or the highest utility, but its "marginal utility" that determines the value of goods. Menger first pointed out: "the value of a specific good, or the value of a certain part of the total amount of goods controlled by an economic subject is equal to the significance of the least important desire satisfaction among various desire satisfactions guaranteed by this total". (Menger, 2013, p. 71) Wieser also believes: "simply put, in a batch of similar property, no matter which one generally has the value of the last utility or marginal utility". (Wieser, 1982, p. 27) Menger explicitly put forward the core viewpoint that "marginal utility" determines the amount of marginal value, which laid the axiological foundation of the Austrian School economics, but Menger's view on marginal value also has some defects. First, Menger pointed out that the value of any part of the total amount of goods was determined by "marginal utility", but he did not indicate how to determine the value of the total amount of goods. Secondly, even the value of any part of the total goods cannot be accurately calculated. Value is essentially an evaluation of goods based on whether the goods can meet people's needs and to what extent they can meet people's needs. Needs and utilities as subjective psychological factors cannot be accurately calculated at all, so the value of goods based on these factors cannot be accurately calculated, too. So the study of the quantity of value has only ordinal or comparative significance. Finally, Menger's discussion of marginal utility theory needs to be further refined and perfected due to his failure to clearly put forward the two classification theories of needs. This task was left to the second generation's scholars of the Austrian School.

\subsection{An Improvement on the Law of Value by Wieser and Bohm-Bawerk}

Wieser solved the problem of determining the value of the total amount of goods by multiplying "marginal utility" and the amount of goods. The second deficiency still persists in the works of following generations and has therefore been criticized by some scholars for a long time. The breakthrough in the third aspect was mainly made by Bohm-Bawerk. According to Menger's point of view, suppose there is a kind of goods corresponding to a desire complex composed of three different desires, the significance of satisfying desires $\mathrm{A}, \mathrm{B}$, and $\mathrm{C}$ is 10,8 , and 6 respectively; desires A, B, and C need 5 units, 4 units, and 3 units of this kind of goods to be fully satisfied, if we have 7 units of goods, what is the value of any unit of goods? Menger thought we would first satisfy desire $A$ in 5 units, then desire B in 2 units, and finally desire $C$ without any satisfaction. Since the last increment of goods is dependent on desire B, the value of any unit of goods is equal to the significance of satisfying desire B. On the basis of Menger, Bohm-Bawerk proposed for the first time the division between "the classification of types" and "the classification of degrees" of needs, and concluded that the value is only related to "the classification of degrees of one need". Wieser's contribution is that he further pointed out that there are more than 10 degrees of human needs and they are not decreasing uniformly at the same rate, the "saturation scales" are different in different needs or even in the same need in different periods of satisfaction, this issue has been discussed in detail above and will not be repeated here. According to the standpoints of the second generation's theorists of the Austrian School, we can still assumed that there is a kind of goods corresponding to a desire complex composed of three different desires, the "saturation scales" of desires D, E, and F are 100, 90, 70, 40, 0; $45,25,15,10,5,0$ and 80,60,40,20, 0 respectively, if we have 6 units of goods, then what is the "marginal utility" guaranteed for the last unit of goods? Wieser believed that we should compare and choose different degrees in different needs. "For goods that are useful in many aspects, the lowest marginal utility that can be obtained must be found from all usages". (Wieser, 1982, p. 17) Therefore, the order of satisfaction should be D (100)-D (90)-F (80)-D (70)-F (60)-E (45), the last unit of goods is dependent on desire $\mathrm{E}$ and the "marginal utility" is 45. In summary, the contribution of Wieser and Bohm-Bawerk to marginal utility theory was that they revised and analyzed the degrees of one need, which made the connotation of "marginal utility" more accurate. Menger believes that "marginal utility" means "the significance of the least important desire satisfaction among various desire satisfactions"; and to the second generation's theorists of the Austrian School, this concept 
improves to the significance of the lowest degree among various kinds of needs on which the last increment of goods is depended.

\section{Conclusion}

The above study shows that the Austrian School does not talk about the value of goods in the sense of kinds, it studies the value of the last increase in the total amount of some kind of goods, that is, marginal value. The most important contribution of marginal utility theory is that it creatively combines the "marginal" concept with the subjective utility value theory. So in the "qualitative" aspect of value, the problem is how to judge the value of the marginal quantity of goods. The marginal quantity of goods always corresponds to a certain degree or specific feeling of a need, rather than to the whole need. Therefore, it is only based on whether the goods can satisfy "a sense of one need", rather than "one of many needs" to judge whether there is value. This is an important difference between marginal utility theory and subjective utility theory. The "quality" of value depends on "a sense of need", which in turn depends on the supply and demand of goods. It is only when the supply of goods is less than the demand that people have a "certain sense of need" for it, and the so-called "quality" of value can be talked about. Conversely, if the supply of a kind of goods is more than the demand, people will be indifferent to it, and will not produce a "sense of need", let alone satisfaction or not. Thus, Menger made it clear that "value is the result of the demand for goods being more than the amount they control". (Menger, 2013, p. 54) Wieser believes that "everything that is truly superfluous and naturally superfluous in the world is called free goods; all other goods are economic goods. Only economic goods can have value". (Wieser, 1982, p. 23) Bohm-Bawerk also believes that "goods are only valuable when the full supply of the goods is not sufficient to meet the needs, or when there is no supply of certain goods, the supply will be insufficient". (Bohm-Bawerk, 1983 , p. 155) So scarcity is the basic presupposition and theoretical premise of marginal utility theory, only in this presupposition and premise can we talk about the "quality" and "quantity" of value.

The transcendence of marginal utility theory over subjective utility theory is that it introduces the "classification of degrees of needs" into the study of value. Subjective utility theory only limits to "the classification of types of needs", so it always regards the importance of the whole kind as the measure of value. As Wieser said, "the importance of the entire category is measured by the entire scale of saturation, especially by its highest number". (Wieser, 1982, p. 13) Take the famous water and diamonds for instance. In subjective utility theory, water is given the same significance as life, while diamonds are evaluated based solely on their slight and transient pleasure, in short, the importance of the two is measured by their total utility or highest utility. However, once this conclusion is applied to real life, the contradiction between use value and exchange value will immediately become apparent. Different from subjective utility theory, marginal utility theory essentially discussed the value from the relationship between marginal quantity of goods and certain degree or individual feeling of needs, proposed the law that "marginal utility" determines the quantity of value, overcame the incompleteness of subjective utility value theory, and completely solved the "value paradox". Marginal utility theory holds that any important kind of needs contains less important specific needs, and any unimportant kind of needs also contains more important specific needs. Therefore, the specific needs in an important category are likely to be less important than the specific needs in an unimportant category. Although water is closely related to human life and can satisfy the needs of the most important kind. However, due to the large amount of water, people's needs for water are basically saturated, the degree or specific feeling of this need is already at a very low level, in other words, its "marginal utility" is close to zero. On the contrary, although diamonds are only concerned with people's needs for pleasure, the number of diamonds is very rare, people's demand for diamonds has been met very modestly, the specific feeling of this need is still at the top of the scale, and "marginal utility" is basically the same as its highest utility. Just because the "marginal utility" of water is so much lower than the "marginal utility" of diamonds, the value of water is so much lower than the value of diamonds. Therefore, it is the marginal utility theory that puts forward the "classification of needs", makes value theory study move from macro generalization to micro analysis, and further refines and improves the subjective utility value theory.

\section{References}

Bohm-Bawerk, E. (1983). The positive theory of capital (Chenduan, Trans.). Beijing: The Commercial Press.

Howey, R. S. (1999). The rise of the marginal utility school: 1870-1889 (Yan Zhijie, Trans.). Beijing: China Social Sciences Publishing House.

Menger, C. (2013). Principles of economics (Liu Jieao, Trans.). Shanghai: Truth \& Wisdom Press.

Smith, A. (1983). An inquiry into the nature and causes of the wealth of nations (Guo Dali \& Wang Yanan, Trans.). Beijing: The Commercial Press. 
Wieser, F. (1982). Natural value (Chen Guoqing, Trans.). Beijing: The Commercial Press.

Yan, Z. J. (1987). Marginalism in economics. Beijing: Peking University Press.

Yuan, G. R. (1991). Introduction to axiology. Beijing: Beijing Normal University Publishing Group.

\section{Copyrights}

Copyright for this article is retained by the author(s), with first publication rights granted to the journal.

This is an open-access article distributed under the terms and conditions of the Creative Commons Attribution license (http://creativecommons.org/licenses/by/4.0/). 